\title{
Inhibitory control of up states and their propagation in the cortical network
}

\author{
Maria V Sanchez-Vives*1,2, Maurizio Mattia3 ${ }^{3}$ Maria Perez-Zabalza1, \\ Vanessa F Descalzo ${ }^{1}$ and Ramon Reig ${ }^{1}$
}

\author{
Address: ${ }^{1}$ IDIBAPS (Institut d'Investigacions Biomèdiques August Pi i Sunyer), Barcelona, Spain, ${ }^{2}$ ICREA (Institució Catalana de Recerca i Estudis \\ Avançats), Barcelona, Spain and ${ }^{3}$ Istituto Superiore di Sanità, Rome, Italy \\ Email: Maria V Sanchez-Vives* - msanche3@clinic.ub.es \\ * Corresponding author
}

from Eighteenth Annual Computational Neuroscience Meeting: CNS*2009

Berlin, Germany. 18-23 July 2009

Published: 13 July 2009

BMC Neuroscience 2009, I0(SuppI I):PI7I doi:I0.II86/I47I-2202-I0-SI-PI7I

This abstract is available from: http://www.biomedcentral.com/I47I-2202/I0/SI/PI7 I

(c) 2009 Sanchez-Vives et al; licensee BioMed Central Ltd.

\section{Introduction}

The cerebral cortex generates spontaneous activity organized in up and down states $(<1 \mathrm{~Hz})$ while in vitro [1]. This activity is similar to the cortical activity occurring during anesthesia and slow wave sleep [2]. Different studies have found that there is a delicate balance of excitation and inhibition during up states. Here we describe the effect of progressive blockade of inhibition on up states.

\section{Methods}

Ferret cortical slices were placed in an interface-style recording chamber and bathed in ACSF containing (in $\mathrm{mM}$ ): $\mathrm{NaCl}, 124 ; \mathrm{KCl}, 3.5 ; \mathrm{MgSO}_{4}, 1 ; \mathrm{NaHPO}_{4}, 1.25$; $\mathrm{CaCl}_{2}, 1.1 ; \mathrm{NaHCO}_{3}, 26$; and dextrose, 10, aerated with $95 \% \mathrm{O}_{2}, 5 \% \mathrm{CO}_{2}$ to a final $\mathrm{pH}$ of 7.4 and $34-35^{\circ} \mathrm{C}$. The local field potential (LFP) was recorded with tungsten electrodes and MUAs (multiunit activity) were estimated as the average power of the relative LFP spectra in the frequency band of $0.2-1.5 \mathrm{~Hz}$ and sampled every $5 \mathrm{~ms}$. This method is qualitatively similar to the one in [3].

\section{Results}

Inhibition was progressively blocked starting with low concentrations of bicuculline methiodide (from $0.2 \mu \mathrm{M}$ ) or gabazine (from $10 \mu \mathrm{M}$ ) in the bath, all the way up to a total blockade. At low concentrations, these $\mathrm{GABA}_{\mathrm{A}}$ antagonists induced changes in the emerging activity without causing epileptiform discharges. The effects that we describe were common for both antagonists. A progressive decrease in the inhibition induced a progressive shortening of the up states to $1 / 4$ the control one, while firing rate during up states increased. The slope of depolarization (repolarization) at the beginning (end) of the up state increased with lesser inhibition, reflecting higher synchronization in the network. The speed of wave propagation also increased progressively with the removal of inhibition. Quantifying these changes has helped us understand how inhibition shapes cortical network activity.

\section{Acknowledgements}

Supported by MICINN, CIDEM and IDIBAPS to MVSV.

\section{References}

I. Sanchez-Vives MV, McCormick DA: Cellular and network mechanisms of rhythmic recurrent activity in neocortex. Nat Neurosci 2000, 3: 1027-1034.

2. Steriade M, Nunez A, Amzica F: A novel slow (< I Hz) oscillation of neocortical neurons in vivo: depolarizing and hyperpolarizing components. J Neurosci 1993, 13:3252-3265.

3. Stark E, Abeles M: Predicting movement from multiunit activity. J Neurosci 2007, 27:8387-8394. 